\title{
Remote-loading of liposomes with manganese- 52 and in vivo evaluation of the stabilities of 52Mn-DOTA and 64Cu-DOTA using radiolabelled liposomes and PET imaging
}

Jensen, Andreas I.; Severin, Gregory W.; Hansen, Anders Elias; Fliedner, Frederikke P.; Eliasen, Rasmus; Parhamifar, Ladan; Kjær, Andreas ; Andresen, Thomas Lars; Henriksen, Jonas Rosager

Published in:

Journal of Controlled Release

Link to article, DOI:

10.1016/j.jconrel.2017.11.006

Publication date:

2018

Document Version

Peer reviewed version

Link back to DTU Orbit

Citation (APA):

Jensen, A. I., Severin, G. W., Hansen, A. E., Fliedner, F. P., Eliasen, R., Parhamifar, L., Kjær, A., Andresen, T. L., \& Henriksen, J. R. (2018). Remote-loading of liposomes with manganese-52 and in vivo evaluation of the stabilities of $\mathrm{Mn}$-DOTA and ${ }^{4} \mathrm{Cu}$-DOTA using radiolabelled liposomes and PET imaging. Journal of Controlled Release, 269, 100-109. https://doi.org/10.1016/j.jconrel.2017.11.006

\section{General rights}

Copyright and moral rights for the publications made accessible in the public portal are retained by the authors and/or other copyright owners and it is a condition of accessing publications that users recognise and abide by the legal requirements associated with these rights.

- Users may download and print one copy of any publication from the public portal for the purpose of private study or research.

- You may not further distribute the material or use it for any profit-making activity or commercial gain

- You may freely distribute the URL identifying the publication in the public portal 


\section{Remote-loading of liposomes with manganese-52 and in vivo evaluation of the stabilities of ${ }^{52} \mathrm{Mn}$-DOTA and ${ }^{64} \mathrm{Cu}$-DOTA using radiolabelled liposomes and PET imaging}

Andreas I. Jensen ${ }^{\mathrm{a}, \mathrm{e}}$, Gregory W. Severin ${ }^{\mathrm{a}, \mathrm{b}, \mathrm{e}}$, Anders E. Hansen ${ }^{\mathrm{c}, \mathrm{d}, \mathrm{e}}$, Frederikke P. Fliedner ${ }^{\mathrm{c}}$, Rasmus Eliasen $^{\mathrm{d}, \mathrm{e}}$, Ladan Parhamifar ${ }^{\mathrm{d}, \mathrm{e}}$, Andreas Kjær ${ }^{\mathrm{c}}$, Thomas L. Andresen ${ }^{\mathrm{d}, \mathrm{e}}$, Jonas R. Henriksen ${ }^{\mathrm{d}, \mathrm{e}, *}$

${ }^{a}$ Center for Nuclear Technologies (DTU Nutech), Technical University of Denmark, Frederiksborgvej 399, DK-4000 Roskilde, Denmark

${ }^{b}$ Department of Chemistry, Michigan State University, East Lansing, MI 48824, USA

${ }^{c}$ Rigshospitalet and University of Copenhagen, Dept. of Clinical Physiology, Nuclear Medicine \& PET and Cluster for Molecular Imaging, 2100 Copenhagen, Denmark

${ }^{d}$ Department of Micro- and Nanotechnology, Technical University of Denmark, Produktionstorvet Building 423, DK-2800 Lyngby, Denmark

${ }^{e}$ Center for Nanomedicine and Theranostics

* Corresponding author: Jonas R. Henriksen, jhen@ nanotech.dtu.dk 


\section{Abstract}

Liposomes are nanoparticles used in drug delivery that distribute over several days in humans and larger animals. Radiolabeling with long-lived positron emission tomography (PET) radionuclides, such as manganese-52 $\left({ }^{52} \mathrm{Mn}, \mathrm{T}^{1} / 2=5.6\right.$ days $)$, allow the imaging of this biodistribution. We report optimized protocols for radiolabeling liposomes with ${ }^{52} \mathrm{Mn}$, through both remote-loading and surface labeling. For comparison, liposomes were also remote-loaded and surface labeled with copper-64 $\left({ }^{64} \mathrm{Cu}, \mathrm{T}^{1} \frac{1}{2}=12.7\right.$ hours $)$ through conventional means. The chelator DOTA was used in all cases. The in vivo stability of radiometal chelates is widely debated but studies that mimic a realistic in vivo setting are lacking. Therefore, we employed these four radiolabeled liposome types as platforms to demonstrate a new concept for such in vivo evaluation, here of the chelates ${ }^{52} \mathrm{Mn}$ DOTA and ${ }^{64} \mathrm{Cu}$-DOTA. This was done by comparing "shielded" remote-loaded with "exposed" surface labeled variants in a CT26 tumor-bearing mouse model. Remote loading (90 min at $55{ }^{\circ} \mathrm{C}$ ) and surface labeling $\left(55{ }^{\circ} \mathrm{C}\right.$ for 2 hours) of ${ }^{52} \mathrm{Mn}$ gave excellent radiolabeling efficiencies of 97$100 \%$ and $98-100 \%$ respectively, and the liposome biodistribution was imaged by PET for up to 8 days. Liposomes with surface-conjugated ${ }^{52} \mathrm{Mn}$-DOTA exhibited a significantly shorter plasma half-life $\left(T_{1 / 2}=14.4 \mathrm{~h}\right)$ when compared to the remote-loaded counterpart $\left(T_{1 / 2}=21.3 \mathrm{~h}\right)$, whereas surface-conjugated ${ }^{64} \mathrm{Cu}$-DOTA cleared only slightly faster and non-significantly, when compared to remote-loaded $(17.2 \pm 2.9 \mathrm{~h}$ versus $20.3 \pm 1.2 \mathrm{~h})$. From our data, we conclude the successful remote-loading of liposomes with ${ }^{52} \mathrm{Mn}$, and furthermore that ${ }^{52} \mathrm{Mn}$-DOTA may be unstable in vivo whereas ${ }^{64} \mathrm{Cu}$-DOTA appears suitable for quantitative imaging.

Keywords: Manganese-52, copper-64, liposomes, DOTA, remote-loading, ionophore 


\section{Introduction}

The development of optimized drug delivery methods for anticancer therapies remains under intense investigation [1]. At the forefront of these efforts is the desire to target cytotoxic chemoand radiotherapeutics directly to cancerous tissue, thereby enhancing efficacy and decreasing doselimiting side-effects. Such targeting can be obtained using nanoparticles, as these accumulate in solid tumors through the enhanced permeation and retention (EPR) effect [2,3]. Liposomes are biocompatible and inexpensive to manufacture, even in large scale, making them arguably the most promising and most intensely researched class of nanoparticles. Labeling liposomes with radionuclides allows scientists to investigate their in vivo behavior and obtain direct quantitative data on biodistribution, drug targeting and clearance. This is an extremely valuable tool in the ongoing research to improve liposomal drug delivery. In addition, radiolabeled liposomes hold promise as delivery vehicles for internal radiotherapy, and as theranostic tools, where radiolabeled diagnostic liposomes predict the efficacy of their therapeutic counterparts [4]. Accordingly, the development and use of radiolabeling techniques for liposomes has become an integral part of the nanomedicine field [5-7].

The in vivo biodistribution of radiolabeled liposomes can be obtained by modern imaging techniques, such as positron emission tomography (PET). Since therapeutically relevant longcirculating liposomes have plasma half-lives of about 10-20 hours in mice, the distribution from the blood stream to accumulating organs occurs within 2-3 days in murine models [8]. This makes the positron-emitting radionuclide ${ }^{64} \mathrm{Cu}\left(\mathrm{t}_{1} / 2=12.7 \mathrm{~h}, \mathrm{E}_{\text {mean }}=278 \mathrm{keV}\right)$ well-suited for preclinical PET imaging in small animals. However, the long-term fate and clearance of liposomes occurring after the initial 2-3 day distribution phase ("post-distribution") cannot be quantified using ${ }^{64} \mathrm{Cu}$. Moreover, the plasma half-life of liposomes is extended in larger animals, being about 30-90 hours in humans [9]. Therefore, comprehensive PET studies of liposomes in animal models beyond rodents also require longer-lived radionuclides. As recent technological advances have made the use of the PET radionuclides zirconium-89 $\left({ }^{89} \mathrm{Zr}, \mathrm{t} 1 / 2=3.3\right.$ days $)$ and iodine- $124\left({ }^{124} \mathrm{I}, \mathrm{t} 1 / 2=4.2\right.$ days $)$ feasible, these have garnered widespread interest in preclinical PET imaging, especially for antibody imaging in the case of $\mathrm{Zr}-89$ [10-12]. However, implementation of these radionuclides in nanomedicine and in general has been limited due to the challenging radiochemistry of the highly oxophilic ${ }^{89} \mathrm{Zr}^{+4}$ ion, and the cascade gamma photons and in vivo deiodination of ${ }^{124} \mathrm{I}$, making 
imaging with these two radionuclides suboptimal. Manganese-52 $\left({ }^{52} \mathrm{Mn}, \mathrm{t}^{1} / 2=5.6\right.$ days $)$ has therefore recently gained interest. In addition to its long physical half-life, ${ }^{52} \mathrm{Mn}$ has a high positron branch $(29.4 \%)$ compared to ${ }^{64} \mathrm{Cu}(17.9 \%)$ and a low positron energy $\left(\mathrm{E}_{\text {mean }}=242 \mathrm{keV}\right)$ which gives a short positron-range and high resolution PET images [13]. In addition, the straight-forward radiochemistry of ${ }^{52} \mathrm{Mn}$, allows the use of standard chelators such as EDTA, DTPA and DOTA. Further, our and associated groups recently reported procedures for preparing ${ }^{52} \mathrm{Mn}$ in purities high enough for use in PET radiotracers such as liposomes $[14,15]$. Its facile chelation by DOTA was also reported, in addition to preliminary evidence for good in vitro and in vivo stability of the MnDOTA chelate. These properties make ${ }^{52} \mathrm{Mn}$ highly useful in preclinical PET imaging, although its high gamma dose may discourage use in humans.

Efficient radiolabeling of liposomes can be enedachieved in two general ways. Either the radionuclide is loaded into the aqueous core of the liposome, known as remote-loading (figure 1). Using this technique, ${ }^{64} \mathrm{Cu}$ has been shown to cross the liposomal membrane and be chelated by encapsulated DOTA with excellent (>95\%) radiolabeling yields [7]. In addition, Edmonds et al. recently reported a procedure for remote-loading ${ }^{52} \mathrm{Mn}$ through encapsulated metal-complexing drugs [16]. Alternatively, radiometals can be bound by chelators on the liposome surface, a method that has also been reported for ${ }^{64} \mathrm{Cu}$ using several different chelators $[17,18]$. In order to rely on results from such surface-labeling (figure 1), the stabilities of the employed chelates must be ascertained. Suboptimal stability will result in the release or transchelation of free radiometal with biodistributions that differ from the investigated tracer $[19,20]$. Indeed, the stability of radiometalchelator complexes placed on the surface of nanoparticles, on antibodies, peptides or small molecules, is paramount for conducting precise quantitative studies. However, the stability of radiometal-chelator complexes exposed directly to the bloodstream is still debated. This is especially true for the ${ }^{64} \mathrm{Cu}$-DOTA chelate, one of the most used radiometal radiolabeling strategies in both research and the clinic [21-23]. As a result, a general reluctance to employ DOTA in imaging studies has been expressed, over concerns of release of the radionuclide from the chelate [24]. Due to the widespread use of ${ }^{64} \mathrm{Cu}$-DOTA, phasing it out would incur significant expenses. For this reason, further investigations are highly warranted to clarify if the reported transchelation from ${ }^{64} \mathrm{Cu}$-DOTA is relevant in quantitative imaging. However, sound methodology for studying the stability of radiometal chelates under realistic in vivo conditions is currently lacking. With an 
expected increase in the preclinical use of the ${ }^{52} \mathrm{Mn}$-DOTA chelate, such studies are also relevant for this radionuclide.

In the present study, we report the radiolabeling of liposomes with ${ }^{52} \mathrm{Mn}$ by remote-loading $\left({ }^{52} \mathrm{Mn}\right.$ remote) and surface labeling ( ${ }^{52} \mathrm{Mn}$-surface), both optimized for quantitative radiochemical yields. In addition, we prepared liposomes remote-loaded $\left({ }^{64} \mathrm{Cu}\right.$-remote $)$ and surface-labeled with ${ }^{64} \mathrm{Cu}$ $\left({ }^{64} \mathrm{Cu}\right.$-surface $)$. All four were prepared as the DOTA chelates, and used to demonstrate a new liposome-based concept for the realistic in vivo evaluation of radiometal-chelate stability. By preparing remote-loaded liposomes, where the chelate is effectively shielded from the bloodstream, and comparing these with surface-labeled chelates that are exposed to the bloodstream, an analysis of the biodistribution and plasma excretion can be used to assess chelate stability. In the present study, this concept was used to investigate the stability of ${ }^{64} \mathrm{Cu}$-DOTA and ${ }^{52} \mathrm{Mn}$-DOTA.

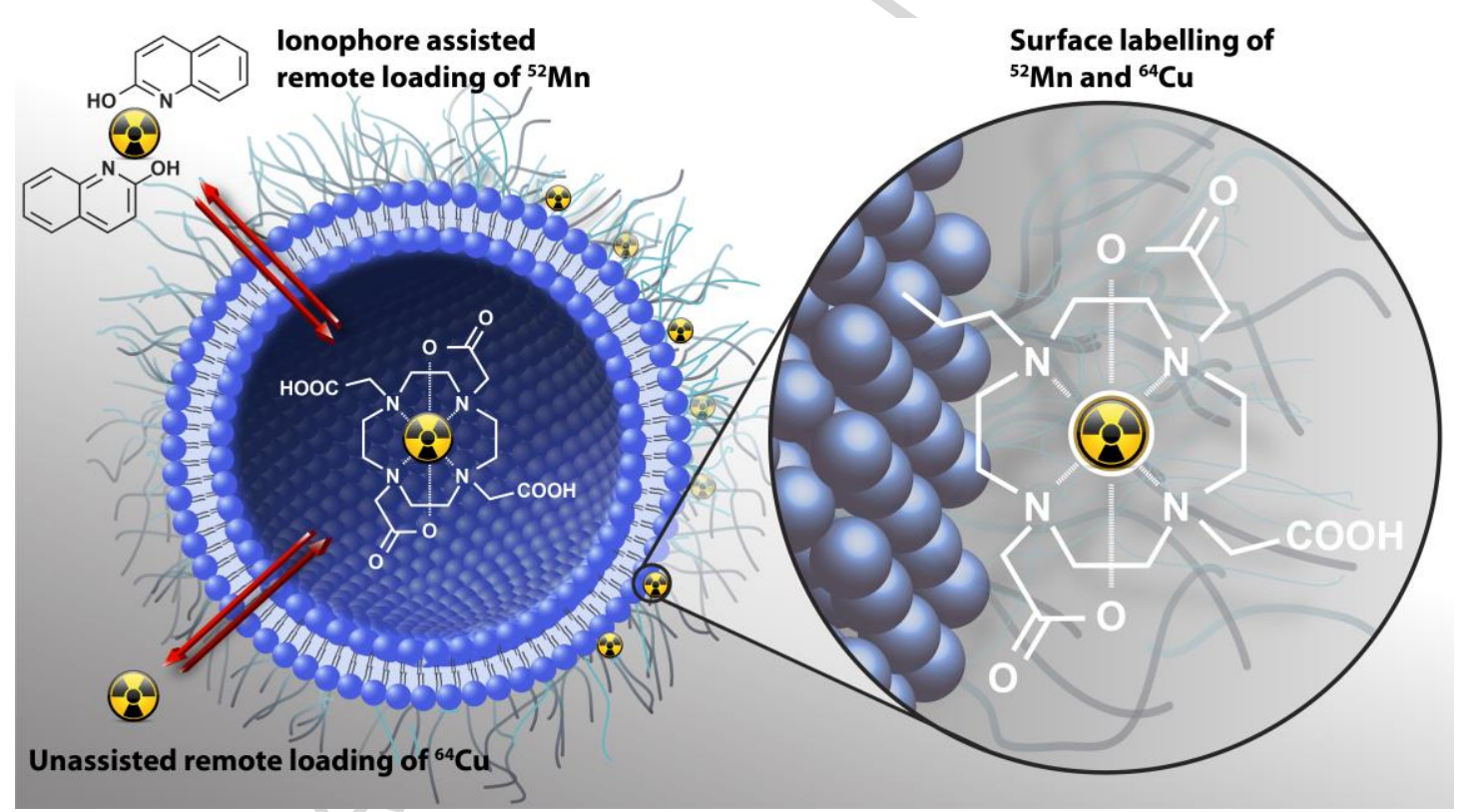

Figure 1: Radiolabeling of liposomes with ${ }^{52} \mathrm{Mn}$ or ${ }^{64} \mathrm{Cu}$ using surface conjugated or encapsulated DOTA chelators. The remote loading of ${ }^{52} \mathrm{Mn}$ is assisted by ionophores that facilitate the transport of the radionuclide across the lipid bilayer, where it is trapped by the high affinity chelator DOTA. The special membrane permeability of copper allows for heat-induced and ionophore-free "unassisted" remote loading of ${ }^{64} \mathrm{Cu}$ into the liposome. Alternatively, the liposome can be surface- 
labeled by ${ }^{52} \mathrm{Mn}$ or ${ }^{64} \mathrm{Cu}$ by direct binding of the radionuclide to DOTA-DSPE lipid conjugates present on the membrane surface.<smiles>Oc1cccc2cccnc12</smiles>

8-HQ<smiles>Oc1ccc2ccccc2n1</smiles>

2-HQ<smiles>Oc1c(I)cc(I)c2cccnc12</smiles>

8-HQ-2I<smiles>Oc1c(Cl)cc(Cl)c2cccnc12</smiles>

8-HQ-2Cl

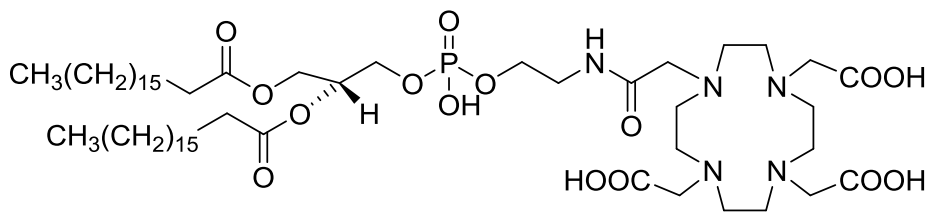

DOTA-DSPE

Chart 1: Structures of ionophores and the DOTA-DSPE lipid conjugate.

\section{Materials and methods}

\subsection{Materials}

All chemicals where purchased from Sigma Aldrich, unless otherwise noted. 1,2Distearoyl-sn-glycero-3-phosphoethanolamine (DSPE) was purchased from Avanti Polar Lipids. 1,4,7,10-Tetraazacyclododecane-1,4,7,10-tetraacetic acid mono-N-hydroxysuccinimide ester (DOTA-NHS ester) was purchased from Macrocyclics, Inc. Premixed stealth liposome mixture (HSPC:Chol:DSPE-PEG2k 565:382:53, molar ratio) was purchased from Lipoid. All chemicals and reagents were of analytical grade, obtained from commercial sources and used without further purification. Sephadex G-25 PD-10 columns (8.3 mL bed volume) were purchased from GE Healthcare. All water was collected from a Milli-Q system (Millipore), unless otherwise noted. Ionophores 8-hydroxyquinoline (8-HQ), 2-hydroxyquinoline (2-HQ), 5,7-diiodo-8hydroxyquinoline (8-HQ-2I), 5,7-dichloro-8-hydroxyquinoline (8-HQ-2Cl) were purchased from Sigma Aldrich (Chart 1). Hiruidin tubes were purchased from Roche, and Zymosan A from Saccharomyces cerevisiae, from Sigma Aldrich. The ELISA kit was purchased from Quidel and measured on a Victor3 microplate reader (Perkin Elmer). 
All radio-TLC analyses were performed on silica gel 60 F254 plates (Merck) with 5\% (w/v) $\mathrm{NH}_{4} \mathrm{OAc}$ in $\mathrm{H}_{2} \mathrm{O}-\mathrm{MeOH}(1: 1)$ as eluent, unless otherwise noted $\left({ }^{52} \mathrm{Mn}\right.$-surface was analyzed on cellulose). Quantification of radio traces was achieved on a MiniGita Star using a Beta Detector GMC probe (both Raytest), or on a Cyclone Plus Storage Phosphor System (Perkin-Elmer). Radioactivity was measured using a Veenstra Instruments dose calibrator VDC-505. Metal content of radioactive preparations was quantified with an ICAP 7000 ICP-OES (Thermo Scientific). Liposome sizes were measured by dynamic light scattering (DLS) on a ZetaPALS (Brookhaven). Liposomes were sized by pressure extrusion using a $10 \mathrm{~mL}$ LIPEX thermobarrel pressure extruder (20 bar nitrogen pressure) [7]. Lipid concentrations were determined by an iCAPQ ICP-MS (Thermo Scientific).

An isotonic TRIS-saline buffer (ISO-TRIS) containing tris(hydroxymethyl) aminomethane (TRIS, $10 \mathrm{mM})$ and $\mathrm{NaCl}(150 \mathrm{mM})$ was prepared and adjusted to $\mathrm{pH} 7.8$ with $\mathrm{HCl} / \mathrm{NaOH}$ (osmolality: $280 \mathrm{mOsm} / \mathrm{kg}$ ). An isotonic HEPES-saline buffer (ISO-HEPES) containing 4-(2-hydroxyethyl)-1-piperazineethanesulfonic acid (HEPES, $10 \mathrm{mM})$ and $\mathrm{NaCl}(150 \mathrm{mM})$ was prepared by mixing molar equal amounts of sodium HEPES salt and free acid HEPES, for a final $\mathrm{pH}$ of 7.4-7.5 and osmolality of $292 \mathrm{mOsm} / \mathrm{kg}$. For EDTA challenge, a $1.0 \mathrm{mM}$ EDTA solution in ISO-HEPES was used (pH 7.4).

\subsection{Preparation of ${ }^{52} \mathrm{Mn}$ and ${ }^{64} \mathrm{Cu}$}

${ }^{52} \mathrm{Mn}$ was produced by proton irradiation of natural chromium using a PETtrace cyclotron (GE Healthcare), following a previously described procedure [15]. In brief, the irradiated chromium was dissolved in hydrochloric acid, and the ${ }^{52} \mathrm{Mn}$ was separated by sequential extractions onto a strong anion exchange resin (AG1x8, Bio-Rad) from ethanol- $\mathrm{HCl}$ mixtures. The purified ${ }^{52} \mathrm{Mn}$ was eluted in dilute aq. $\mathrm{HCl}(0.1 \mathrm{M})$ for use in the liposome labeling experiments. Samples from the elution were analyzed for metal ion content by inductively coupled plasma optical emission spectroscopy (ThermoScientific iCAP 6000 Series) in aq. $\mathrm{HCl}(0.3 \mathrm{M})$ against dissolved chloride-salt standards of $\mathrm{Mn}, \mathrm{Cr}, \mathrm{Co}, \mathrm{Fe}$, and $\mathrm{Zn}$. For metal content in the ${ }^{52} \mathrm{Mn}$ preparations, see Supplementary Materials S1.

${ }^{64} \mathrm{Cu}$ was produced by proton irradiation of an electroplated ${ }^{64} \mathrm{Ni}$ target, and purified by anion exchange chromatography in aqueous $\mathrm{HCl}$ media. The ${ }^{64} \mathrm{Cu}$ was ultimately obtained in aq. $\mathrm{HCl}(1.0 \mathrm{M})$, and dried under argon flow for use in radiolabeling, as previously described [25]. 


\subsection{Synthesis of DSPE-DOTA}

DOTA-NHS ester (34 mg, $45 \mu \mathrm{mol})$ and DSPE (28 mg, $37 \mu \mathrm{mol})$ were dissolved in dichloromethane $(8 \mathrm{~mL}) . N, N$-diisopropylethylamine $(140 \mathrm{uL}, 0.84 \mathrm{mmol})$ was added and the reaction proceeded overnight at room temperature (RT). The solvent was removed under reduced pressure and the product purified by semi-preparative HPLC (Waters 600 Pump \& Controller, Waters 2489 UV/Visible detector) using a Waters XTerra ${ }^{\circledR} \mathrm{C}_{8} 5 \mu \mathrm{m}(10 \mathrm{x} 150 \mathrm{~mm})$ column. Eluent: (A) $5 \%$ acetonitrile $+0.1 \%$ trifluoroacetic acid in water, (B) $0.1 \%$ trifluoroacetic acid in acetonitrile. Gradient profile; linear gradient from $50 \%$ B to $100 \%$ B over 15 min followed by 5 min at $100 \%$ B. Flow rate; $5 \mathrm{~mL} / \mathrm{min}$. DSPE-DOTA was isolated as a broad peak from 11-18 min. Fractions were analysed by MALDI-TOF and those containing the desired product and no detectable impurities were pooled. The product was lyophilised to obtain a white powder $(21 \mathrm{mg}$, $19 \mu \mathrm{mol}, 50 \%$ yield, Chart 1). MALDI-TOF MS (positive mode): Calc. $\mathrm{M}+\mathrm{H}^{+}$: $1134.8 \mathrm{Da}$., Obs. $\mathrm{M}+\mathrm{H}^{+}$: $1134.7 \mathrm{Da} .{ }^{1} \mathrm{H}-\mathrm{NMR}(400 \mathrm{MHz}$, chloroform-d.methanol-d, 9:1): $\delta 5.1(\mathrm{~m}, 1 \mathrm{H}), 4.3(\mathrm{~m}, 2 \mathrm{H})$, $4.1(\mathrm{~m}, 2 \mathrm{H}), 4.0-2.5$ (br. m, 28H), $2.2(\mathrm{~m}, 4 \mathrm{H}), 1.4(\mathrm{~m}, 4 \mathrm{H}), 1.2(\mathrm{~m}, 56 \mathrm{H}), 0.8(\mathrm{~m}, 6 \mathrm{H})$. For NMR spectrum, see Supplementary Materials S2.

\subsection{Preparation of liposomes (DOTA1\%, LIP405, LIP780)}

For surface loading: A stealth lipid mixture containing 1.0 mol\% DSPE-DOTA (HSPC:Chol:DSPE-PEG2k:DSPE-DOTA 560:378:52:10, molar ratio) was freeze-dried from tertbutanol:water (9:1). The obtained lyophilizate was hydrated with an aqueous ISO-HEPES buffer (see section 2.1) at $65{ }^{\circ} \mathrm{C}$ for $60 \mathrm{~min}$ and subsequently sized by pressure extrusion, furnishing DOTA1\% liposomes. The average liposome size was $102 \mathrm{~nm}$ (PDI 0.005) as measured by DLS, and the lipid concentration was $27 \mathrm{mM}$ based on measuring the phosphorous content by ICP-MS. For remote loading: Liposomes entrapping $10 \mathrm{mM}$ DOTA were prepared with internal $\mathrm{pH}$ values of 4.05 (LIP405) or 7.80 (LIP780). Stealth liposome mixture was hydrated in either a DOTA-HEPES buffer (10 mM HEPES, $150 \mathrm{mM} \mathrm{NaCl}, 10 \mathrm{mM}$ DOTA, pH 4.05, $304 \mathrm{mOsm} / \mathrm{kg}$ ) or a DOTA-TRIS buffer (10 mM TRIS, $150 \mathrm{mM} \mathrm{NaCl}, 10 \mathrm{mM}$ DOTA, pH 7.80, $299 \mathrm{mOsm} / \mathrm{kg}$ ), at $65{ }^{\circ} \mathrm{C}$ for $60 \mathrm{~min}$. Subsequently the liposomes were sized by pressure extrusion. The external medium of the DOTAHEPES liposomes was replaced with ISO-HEPES buffer and the external media of the DOTATRIS liposomes with ISO-TRIS using dialysis or tangential flow filtration, as previously described [7]. The size and lipid concentration were $99 \mathrm{~nm}$ (PDI 0.033) and $63 \mathrm{mM}$ for the DOTA-HEPES liposomes and $102 \mathrm{~nm}$ (PDI 0.043) and $14.7 \mathrm{mM}$ for the DOTA-TRIS liposomes. 
2.5 Remote-loading of liposomes with ${ }^{52} \mathrm{Mn}$ and ${ }^{64} \mathrm{Cu}$ (general procedures)

Loading of ${ }^{52} \mathrm{Mn}$ : To a solution of ${ }^{52} \mathrm{Mn}$ in $0.1 \mathrm{M}$ aq. $\mathrm{HCl}$ (4-5 MBq) was added a solution of ionophore in ethanol (8HQ, 2HQ, 8HQ-2I or 8HQ-C21, $128 \mu \mathrm{L}, 50 \mu \mathrm{M}$ ). The mixture was dried in HPLC vials at $120{ }^{\circ} \mathrm{C}$ under an argon stream (maximum 10 minutes). To the dry mixtures was added LIP480 or LIP780 (320 $\mu \mathrm{L}, 10 \mathrm{mM}$ lipid) and the reaction mixtures were magnetically stirred at $55{ }^{\circ} \mathrm{C}$. At specified time-points (typically $1 \mathrm{~h}, 2 \mathrm{~h}$ and $3 \mathrm{~h}$ ), the mixtures were analyzed by radioTLC and size-exclusion chromatography (SEC). For SEC analysis, an aliquot (80 $\mu \mathrm{L})$ was mixed with a solution of EDTA in ISO-HEPES buffer $(1.0 \mathrm{mM}$ EDTA, $80 \mu \mathrm{L})$ and allowed to equilibrate for 5-10 minutes. Mixtures were then applied to a PD-10 cartridge and eluted with ISO-HEPES. Two consecutive fractions of $5.5 \mathrm{~mL}$ each were collected and their radioactivity quantified on a dose-calibrator. The PD-10 derived encapsulation efficiency was determined as the ratio of the radioactivity in the liposome fraction (fraction one, $5.5 \mathrm{~mL}$ ) to the total radioactivity in fraction one and two combined $(11 \mathrm{~mL})$. Radio-TLC showed two spots corresponding to ${ }^{52} \mathrm{Mn}$-DOTA $\left(\mathrm{R}_{\mathrm{f}}=0.3\right)$ and free unloaded ${ }^{52} \mathrm{Mn}\left(\mathrm{R}_{\mathrm{f}}=0\right)$. The TLC derived encapsulation efficiency was determined as the ratio of the ${ }^{52} \mathrm{Mn}$-DOTA activity to the total radioactivity in all peaks combined. After 3 hours, the remaining mixture was mixed 1:1 with a solution of EDTA in ISO-HEPES (1.0 mM EDTA) and allowed to equilibrate for 24 hours at room temperature (RT). The mixture was then analyzed by PD-10 as described above. The loading experiments were conducted at $10 \mathrm{mM}$ lipid, $20 \mu \mathrm{M}$ ionophore and a ${ }^{52} \mathrm{Mn}$ radioactivity concentration of $13 \mathrm{MBq} / \mathrm{mL}$ and performed in triplicate. Loading of ${ }^{64} \mathrm{Cu}$ : Remote-loading of ${ }^{64} \mathrm{Cu}$ into liposomes was conducted as previously described $[3,7]$.

2.6 Ionophore concentration effect on the remote-loading of liposomes with ${ }^{52} \mathrm{Mn}$

Ionophore concentrations of 2, 10, 20 and $50 \mu \mathrm{M}$ were compared. A solution of ${ }^{52} \mathrm{Mn}$ in $0.1 \mathrm{M}$ aq. $\mathrm{HCl}(20 \mu \mathrm{L}$, about $930 \mathrm{kBq})$ was mixed with a $50 \mu \mathrm{M}$ solution of $8 \mathrm{HQ}-2 \mathrm{Cl}$ in ethanol $(2 \mu \mathrm{M}: 8 \mu \mathrm{L}$, $10 \mu \mathrm{M}: 40 \mu \mathrm{L}, 20 \mu \mathrm{M}: 80 \mu \mathrm{L}, 50 \mu \mathrm{M}: 200 \mu \mathrm{L}$ ). The resulting mixtures were dried at $120{ }^{\circ} \mathrm{C}$ under a stream of argon $(2 \mu \mathrm{M}: 1 \mathrm{~min}, 10 \mu \mathrm{M}$ : $1.5 \mathrm{~min}, 20 \mu \mathrm{M}: 2 \mathrm{~min}, 50 \mu \mathrm{M}: 5 \mathrm{~min})$. The dry ${ }^{52} \mathrm{Mn}-$ ionophore complex was mixed with TRIS buffer $(64 \mu \mathrm{L})$ and heated to $55{ }^{\circ} \mathrm{C}$. Then a dispersion of LIP780 (14.7 mM lipid, $136 \mu \mathrm{L})$ was added for a final lipid concentration of $10 \mathrm{mM}$ and a ${ }^{52} \mathrm{Mn}$ radioactivity concentration of $5 \mathrm{MBq} / \mathrm{mL}$. The mixtures were stirred at $55{ }^{\circ} \mathrm{C}$ and analyzed by 
radio-TLC at 1, 8, 15, 30, 60 and 120 minutes. This experiment was done in triplicate $(\mathrm{n}=3)$ for each ionophore concentration.

\subsection{Surface radiolabeling of liposomes with ${ }^{52} \mathrm{Mn}$ and ${ }^{64} \mathrm{Cu}$}

Surface labeling of DOTA1\% liposomes with ${ }^{52} \mathrm{Mn}$ or ${ }^{64} \mathrm{Cu}$ was conducted at 10 and $20 \mathrm{mM}$ final lipid concentrations. Surface-labeling with ${ }^{\mathbf{5 2}} \mathbf{M n}$ : ISO-HEPES buffer (10 mM lipid: $188 \mu \mathrm{L}, 20$ $\mathrm{mM}$ lipid: $70 \mu \mathrm{L}$ ) was mixed with a solution of ${ }^{52} \mathrm{Mn}$ in ISO-HEPES buffer (13.3 $\left.\mu \mathrm{L}, 3.9-4.7 \mathrm{MBq}\right)$. To this solution was added a dispersion of DOTA1\% liposomes (27 mM lipid concentration) in ISO-HEPES (10 mM: $119 \mu \mathrm{L}, 20 \mathrm{mM}: 237 \mu \mathrm{L}$ ) for final lipid concentrations of $10 \mathrm{mM}$ or $20 \mathrm{mM}$. These mixtures were heated to $55{ }^{\circ} \mathrm{C}$ while stirred magnetically. After $1 \mathrm{~h}, 2 \mathrm{~h}$ and $3 \mathrm{~h}$, the mixtures were analyzed by radio-TLC on cellulose (eluted in $100 \mathrm{mM}$ citrate, $\mathrm{pH} 8.4$ ) and on PD-10 columns as described in section 2.5. ${ }^{52} \mathrm{Mn}$-DOTA-DSPE was shown not to elute on TLC, whereas free ${ }^{52} \mathrm{Mn}$ could be quantified as ${ }^{52} \mathrm{Mn}$-Citrate $(\mathrm{Rf}=1.0)$. Subsequently, a $24 \mathrm{~h}$ EDTA challenge study was conducted as also described in section 2.5. Surface-labeling with ${ }^{64} \mathrm{Cu}$ : A dispersion of DOTA1\% liposomes in ISO-HEPES (500 $\mu \mathrm{L}, 10$ or $20 \mathrm{mM}$ lipid) was added to dry ${ }^{64} \mathrm{CuCl}_{2}(98-106 \mathrm{MBq})$. The resulting mixtures were magnetically stirred at $55{ }^{\circ} \mathrm{C}$. At $1 \mathrm{~h}, 2 \mathrm{~h}$ and $3 \mathrm{~h}$, the reaction mixtures were challenged with $1 \mathrm{mM}$ EDTA in ISO-HEPES as described in section 2.5. Radio-TLC and PD10 were conducted, followed by a $24 \mathrm{~h}$ EDTA challenge as described in section $2.5 .{ }^{64} \mathrm{Cu}$-DOTADSPE was shown not to elute on TLC, whereas free ${ }^{64} \mathrm{Cu}$ could be quantified as ${ }^{64} \mathrm{Cu}$-EDTA $(\mathrm{Rf}=$ 0.7). These experiments were done in triplicate $(n=3)$ for each lipid concentration.

\subsection{Preparation of radiolabeled liposomes for in vivo experiments}

All radiolabeled liposome preparations for in vivo use were $20 \mathrm{mM}$ lipid, $2.0 \mathrm{~mL}$ and $12.5 \mathrm{MBq} / \mathrm{mL}$ $\left({ }^{52} \mathrm{Mn}\right)$ or $75 \mathrm{MBq} / \mathrm{mL}\left({ }^{64} \mathrm{Cu}\right)$ at time of injection. ${ }^{52} \mathrm{Mn}$-remote: A solution of ${ }^{52} \mathrm{Mn}$ in $0.1 \mathrm{M} \mathrm{HCl}$ (25 MBq, $95 \mu \mathrm{L}$ ) was mixed with a solution of 8HQ-2Cl in ethanol (50 $\mu \mathrm{M} 8 \mathrm{HQ}-2 \mathrm{Cl}, 1036 \mu \mathrm{L})$. The mixture was taken to dryness at $120{ }^{\circ} \mathrm{C}$ under an argon stream $(5 \mathrm{~min})$. A dispersion of LIP780 $(14.7 \mathrm{mM}$ lipid, $1750 \mu \mathrm{L})$ was added and the reaction mixture was magnetically stirred at $55{ }^{\circ} \mathrm{C}$ for $90 \mathrm{~min}$. Then, empty liposomes were added to reach a lipid concentration of $20 \mathrm{mM}$. PD-10 analysis and radio-TLC were conducted as described above (section 2.5), showing 94\% and 99\% loading efficiency respectively. ${ }^{52} \mathrm{Mn}$-surface: $25 \mathrm{MBq}$ in $0.1 \mathrm{M} \mathrm{HCl}(95 \mu \mathrm{L})$ was dried at $120{ }^{\circ} \mathrm{C}$ using argon (5 min). To the dry ${ }^{52} \mathrm{Mn}$ was added ISO-HEPES $(520 \mu \mathrm{L})$ and the mixture was magnetically stirred at $55{ }^{\circ} \mathrm{C}$ for $10 \mathrm{~min}$. DOTA1\% liposomes $(1480 \mu \mathrm{L}, 27 \mathrm{mM}$ lipid) was added 
and the stirring was continued for $2 \mathrm{~h}$ at $55{ }^{\circ} \mathrm{C}$. PD-10 analysis and radio-TLC were conducted as described above (section 2.5) showing 99\% and $100 \%$ loading efficiency respectively. ${ }^{64} \mathbf{C u}-$ remote: To a vial containing dry $\mathrm{CuCl}_{2}(360 \mathrm{MBq})$ was added LIP780 liposomes (14.7 mM lipid, $1750 \mu \mathrm{L})$ and the reaction mixture was magnetically stirred at $55^{\circ} \mathrm{C}$ for $75 \mathrm{~min}$. Then, empty liposomes were added to reach a lipid concentration of $20 \mathrm{mM}$. PD-10 analysis and radio-TLC were conducted as described above (section 2.5) showing 97\% and 100\% loading efficiency respectively. ${ }^{64} \mathrm{Cu}$-surface: To a vial containing dry $\mathrm{CuCl}_{2}$ (360 MBq) was added DOTA1\% liposomes $(27 \mathrm{mM}$ lipid, $1480 \mu \mathrm{L}$ ). The reaction mixture was magnetically stirred at $55^{\circ} \mathrm{C}$ for $2 \mathrm{~h}$. Finally, an aliquot of the reaction mixture $(80 \mu \mathrm{L})$ was mixed with $1.0 \mathrm{mM}$ EDTA in ISO-HEPES (80 $\mu \mathrm{L})$ and after 510 minutes of equilibration, PD-10 and radio-TLC analyses were conducted as described above (section 2.5). A loading efficiency of $93 \%$ and $100 \%$ was observed for PD-10 and TLC respectively. The loading efficiency was also analyzed on HPLC-SEC (Sephadex 25G superfine, prepacked in a GE Healthcare Tricorn 5/200 column, $0.4 \mathrm{ml} / \mathrm{min}$ ISO-TRIS), which showed 98\% loading efficiency.

\subsection{Animal model}

All experimental procedures were approved by, and conducted under the guidelines of The Danish Animal Experiments Inspectorate. Immunocompetent Balb/C mice (Charles River Laboratories) were inoculated subcutaneously with $3 \times 10^{5}$ CT26 cancer cells (murine colon carcinoma, ATCC, Virginia, US) in $100 \mu \mathrm{L}$ medium in the right flank. Tumor sizes were calculated from the formula tumor size $=0.5 \cdot\left(L^{2} \cdot W\right)$, where $\mathrm{L}$ is the length and $\mathrm{W}$ is the width of the tumor, measured by external caliper. The tumors were monitored and included in the study when reaching a tumor size of $\sim 150 \mathrm{~mm}^{3}$.

\subsection{PET imaging and data analysis}

Mice were slowly injected via the tail vein with $200 \mu \mathrm{L}$ radiolabeled liposomes containing either 12-13 $\mathrm{MBq}{ }^{64} \mathrm{Cu}$ or $2-3 \mathrm{MBq}{ }^{52} \mathrm{Mn}$. During the scan procedures all mice were kept anaesthetized with 3\% sevoflurane (Abbott Scandinavia AB, Solna, Sweden) mixed with 35\% $\mathrm{O}_{2}$ and $65 \% \mathrm{~N}_{2}$ and placed on a heating pad. Two mice were positioned side-by-side, separated by a $6 \mathrm{~mm}$ polystyrene block for PET/CT imaging using an Inveon® small animal PET/CT system with CT based PET image attenuation (Siemens Medical Systems, Malvern, PA, USA). The protocol included a CT scan followed by a PET scan. Acquisition times for PET scans were performed to provide sufficient 
numbers of counts and ranged from 5 to 15 minutes. Reconstruction of PET scans were performed using maximum a posteriori (MAP) reconstruction algorithm (voxel size: $0.815 \times 0.815 \times 0.796 \mathrm{~mm}$; resolution (FWHM) $1.2 \mathrm{~mm}$ ). Imaging time points for both the ${ }^{64} \mathrm{Cu}$ and ${ }^{52} \mathrm{Mn}$ isotope was $40 \mathrm{~min}$, $2 \mathrm{~h}, 6.5 \mathrm{~h}, 16 \mathrm{~h}, 24 \mathrm{~h}$, and $30 \mathrm{~h}$ after injection (all groups). Additionally, three time points were imaged for the ${ }^{52} \mathrm{Mn}$ isotope at day 4, 6, and 8 after injection (group 1 and 2).

Image analysis was performed using commercially available Inveon software (Siemens Medical Systems, Malvern, PA, USA). Regions of interest (ROIs) were manually drawn based on the co-registered PET/CT images. The following ROIs were constructed; tumors (complete volume delineated), liver, spleen, bladder and blood. Blood activity was estimated from a constructed ROI covering the ventricles of the heart. ROIs were subsequently segmented to only include the voxels displaying above $80 \%$ of maximum activity with the original ROI and clearly delineated the heart ventricles. For the ${ }^{52} \mathrm{Mn}$ images ROIs were drawn to cover the femoral bone and these were subsequently segmented, based on CT, to exclude solid bone and only include central located bone-marrow for detection of accumulation of ${ }^{52} \mathrm{Mn}$. From the obtained uptake values all data was calculated as \% ID/g for each organ.

Statistics on in vivo PET data were calculated in PRISM (version 7.02) using Tukey's multiple comparison test with post hoc two-way ANOVA. For tumor data, one-way ANOVA with Tukey's multiple comparison test was performed, due to unequal sample sizes. For late imaging points where only the two ${ }^{52} \mathrm{Mn}$ liposome types were available, Student's t-test (two-tailed, unpaired) was used. Plasma half-lives were calculated for all five individual mice and also compared by Tukey's multiple comparison test with post hoc ANOVA in PRISM.

\subsection{Well counting}

After sacrificing animals, tumor, spleen, liver, pancreas, and muscle tissue was collected from three mice in each group and gamma counted (Wizard Well Counter, Perkin Elmer, US). Mice were sacrificed 4 days after injection for ${ }^{64} \mathrm{Cu}$-surface and ${ }^{64} \mathrm{Cu}$-remote, and 11 days after injection for ${ }^{52} \mathrm{Mn}$-surface and ${ }^{52} \mathrm{Mn}$-remote. Tissue samples were counted for 1 minute for ${ }^{52} \mathrm{Mn}$ and 10 minutes for ${ }^{64} \mathrm{Cu}$. Results were collected as CPM (counts per minute) and corrected for decay and counting efficiency. Final results are presented as \% ID/g calculated from CPM values and the weight of the specific organ. Well-counting data were compared for each radionuclide by Student's t-test (twotailed, unpaired). 

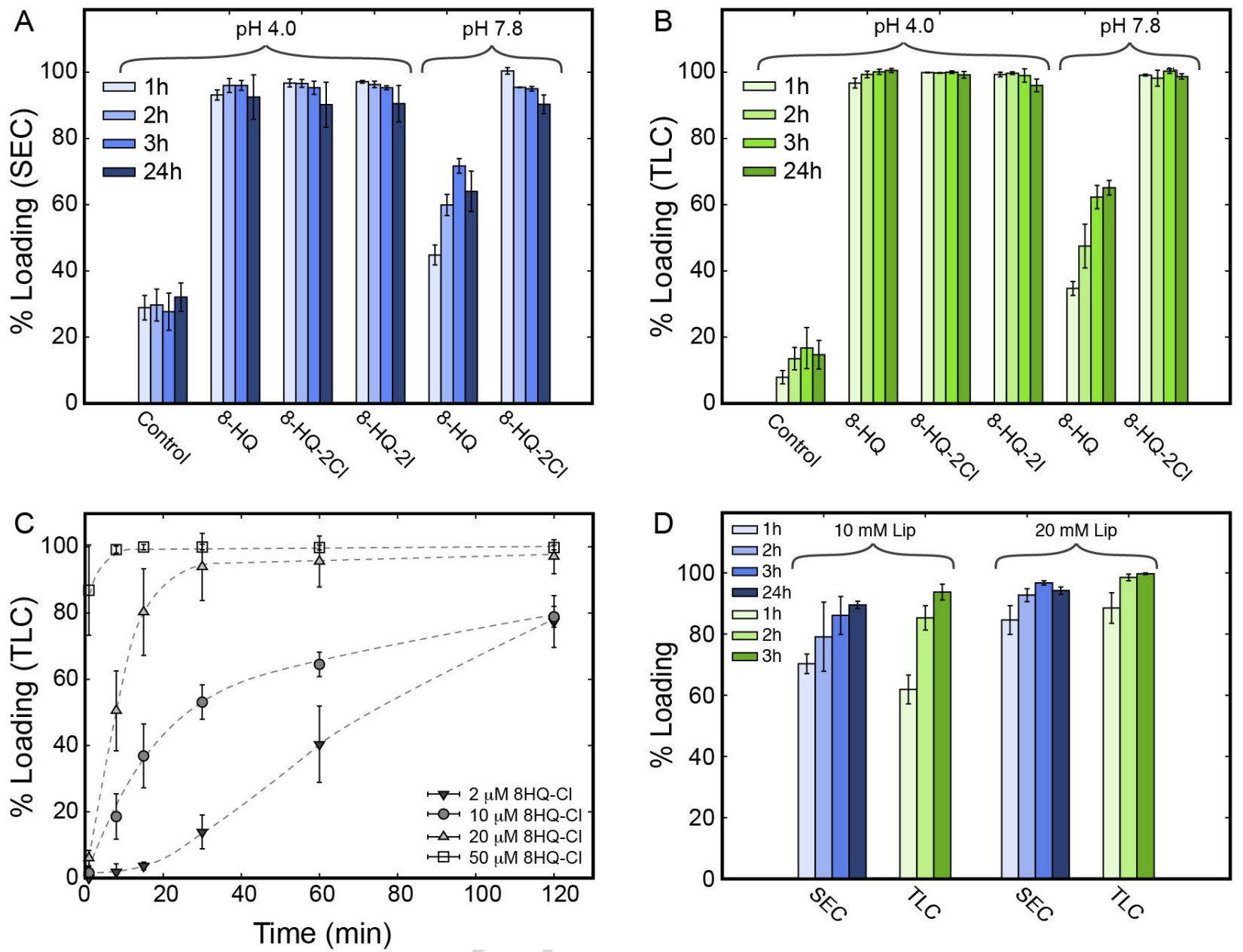

Figure 2: Radiolabeling of liposomes with ${ }^{52} \mathrm{Mn}$. (A+B) Comparison of liposome loading using different ionophores, $8 \mathrm{HQ}, 8 \mathrm{HQ}-2 \mathrm{Cl}$ and $8 \mathrm{HQ}-2 \mathrm{l}$ at internal liposome $\mathrm{pH}$ values of 4.0 or 7.8 . The loading efficiency was determined by size-exclusion chromatography (SEC, A) as well as by radio-TLC (B) at $1 \mathrm{~h}, 2 \mathrm{~h}$ and $3 \mathrm{~h}$. SEC and TLC analyses were in addition conducted after a 24 hour EDTA challenge to elucidate the loading stability. A control experiment without ionophores was included. (C) Comparison of the loading rate of ${ }^{52} \mathrm{Mn}$ into liposomes using different ionophore concentrations. The rate was assessed at 2, 10, 20 and 50 $\mu \mathrm{M} 8 \mathrm{HQ}-\mathrm{Cl}$ using radio-TLC. All remote loading experiments were conducted at $55^{\circ} \mathrm{C}, 10 \mathrm{mM}$ lipid, $12-15$ $\mathrm{MBq}{ }^{52} \mathrm{Mn} / \mathrm{ml}$ and $20 \mu \mathrm{M}$ ionophore (A+B). (D) Surface labeling of ${ }^{52} \mathrm{Mn}$ onto DOTA1\% liposomes. The loading efficiency was assessed by SEC and radio-TLC after $1 \mathrm{~h}, 2 \mathrm{~h}$ and $3 \mathrm{~h}$ for lipid concentrations of 10 and $20 \mathrm{mM}$. SEC analysis was in addition conducted after a 24 hour EDTA challenge. All experiments were conducted at $55^{\circ} \mathrm{C}$ and $12-15 \mathrm{MBq} / \mathrm{mL}$. 


\section{Results and discussion}

\subsection{Radiochemistry}

We prepared liposomes surface labeled or remote loaded with ${ }^{52} \mathrm{Mn}$ or ${ }^{64} \mathrm{Cu}$ and compared the resulting four liposome types head to head in vivo in a murine tumor model to assess the stability of the DOTA chelates. As new methodology for ${ }^{52} \mathrm{Mn}$ radiolabeling of liposomes is reported here, these procedures were investigated in detail and optimized.

General radiochemistry: Radiolabeling efficiencies were measured by both PD-10 and radio-TLC, giving slightly different results. The reason for this is imperfect separation of small molecules and liposomes by PD10 resulting in a slight overlap of the large molecule and the small molecule peaks, which occurs between 5.5 and $6.0 \mathrm{~mL}$. Since we only considered the elution up to $5.5 \mathrm{~mL}$ as belonging to the liposomes, the PD-10 results are generally artificially lower than the TLC results, as the overlapping region occurs after $5.5 \mathrm{~mL}$. In the preparation of ${ }^{64} \mathrm{Cu}$-surface for in vivo experiments PD-10 analysis only gave 93\% labeling efficiency (TLC gave 100\%), for which reason this preparation was also analyzed on SEC HPLC, giving 98\% labeling efficiency. Radio-TLC analyses of ${ }^{64} \mathrm{Cu}$-remote and ${ }^{52} \mathrm{Mn}$-remote were based on previous observations that encapsulated DOTA-radiometal chelates will elute freely on silica if the liposomes containing them are spotted and the spot is allowed to dry. DOTA does not react with free ${ }^{64} \mathrm{Cu}$ or ${ }^{52} \mathrm{Mn}$ on silica, which was tested by applying free radiometal and DOTA-encapsulating liposomes in the same spot and allowing it to dry. In that case, all radioactivity stayed at the origin. This allows determination of loading efficiency by radio-TLC. Note that EDTA was added in the analyses of ${ }^{64} \mathrm{Cu}$-remote and ${ }^{52} \mathrm{Mn}$-remote to also elute potential free radiometal (Cu-EDTA Rf: 0.7, Mn-EDTA Rf: 0.4, broad peak). ${ }^{52} \mathrm{Mn}$-surface was analyzed by radio-TLC in a different system, on cellulose eluted with a citrate buffer. Here, free ${ }^{52} \mathrm{Mn}$ is complexed by the citrate $(\mathrm{Rf}=1.0$ ), making it possible to distinguish it from ${ }^{52} \mathrm{Mn}$ bound to liposomes (non-eluting). Note that the ionophore-radiometal complexes do not elute in the employed TLC systems.

Remote loading of ${ }^{52} \mathrm{Mn}\left({ }^{52} \mathrm{Mn}-\right.$ remote): In this method, loading of the radionuclide is facilitated by a strong transmembrane cation gradient as previously described for ${ }^{64} \mathrm{Cu}$ [7]. In initial attempts, liposomes entrapping DOTA were loaded with ${ }^{52} \mathrm{Mn}$ without the use of ionophores, which resulted in a poor loading efficiency ( $<30 \%$ on PD-10 and $<20 \%$ on TLC, see Control in Fig. 2 A-B). 
Because of this, the ionophores 2-HQ and 8-HQ were included to assist the diffusion of ${ }^{52} \mathrm{Mn}$ across the lipid bilayer. Little increase in loading efficiency was gained by adding 2-HQ (data not shown). However, the use of 8-HQ resulted in increased loading (>70\% on PD-10, $3 \mathrm{~h}$ loading) for liposomes entrapping DOTA at $\mathrm{pH} 7.8$ (Fig $2 \mathrm{~A}-\mathrm{B}$ ). In order to push the equilibrium of the loading/exchange reaction $\left(\mathrm{Mn}(\mathrm{IO})_{\mathrm{x}}+\operatorname{DOTA}(\mathrm{lip}) \leftrightarrows \mathrm{MnDOTA}(\mathrm{lip})+\mathrm{x} \mathrm{IO}\right.$, where IO is short for ionophore) further, two optimization strategies were devised. In one approach, the ${ }^{52} \mathrm{Mn}$-ionophore complex stability was reduced by including chloro (8-HQ-2Cl) or iodo (8-HQ-2I) electron withdrawing substituents on the quinolone ring of the ionophore. In the second approach, the binding affinity of the entrapped chelator and ionophore was reduced by lowering the $\mathrm{pH}$ value and hence increasing the protonation of these inside the liposome lumen. For liposomes entrapping DOTA at $\mathrm{pH} 4.0$ or $\mathrm{pH} 7.8$, improved loading efficiency (>95\% loading on PD-10 and >98\% loading on Radio-TLC) was obtained when 8-HQ-2Cl was used as ionophore (Fig. 2A-B). Equally high loading efficiencies were obtained for liposomes entrapping DOTA at $\mathrm{pH} 4.0$ when using 8HQ and 8-HQ-2I as ionophores. 8-HQ-2I was only tested for liposomes entrapping DOTA at $\mathrm{pH}$ 4.0 as its poor solubility in EtOH limited its use. Complete loading (>95\%) was reached within the first hour in all cases except for 8-HQ at $\mathrm{pH}$ 7.8. In the latter case, a gradual increase in loading efficiency was observed as a function of time. These results showed that the loading efficiency, and thereby the exchange of the radiometal from the ionophore complex to DOTA, could be optimized by destabilization of the ${ }^{52} \mathrm{Mn}$-ionophore complex using electron-withdrawing substituents. Similar reduction in the binding affinity of copper with 8-HQ versus 8-HQ-2Cl has previously been reported [26] which substantiates the claim of destabilization of the ${ }^{52} \mathrm{Mn}$-ionophore complex. Moreover, a reduction of the $\mathrm{pH}$ inside the liposomes from 7.8 to 4.0 resulted in complete loading for 8-HQ, 8-HQ-2Cl and 8-HQ-2I.

Both remote-loaded and surface-labeled liposomes exhibited high stability of the radiolabel when exposed to an EDTA challenge for 24 hours. Less than $5 \%$ decline in loading efficiency (Fig. 2A-B) was observed between the 3- and 24-hour time-point. Hence, unloading of ${ }^{52} \mathrm{Mn}$ in vivo is highly unlikely as long as the liposomes remain intact in vivo, which they have been shown in previous studies to be $[3,25]$. The high loading efficiencies (>95\%) obtained for ${ }^{52} \mathrm{Mn}$ in this study compares to previous results obtained for the remote loading of ${ }^{64} \mathrm{Cu}[7,27]$. In previous studies, we tested stealth liposomes remote-loaded with ${ }^{64} \mathrm{Cu}$-DOTA both with and without ionophores against serum, finding that no leakage of the radioactivity occurred [3]. Likewise, the stability of the DOTA complexes of ${ }^{52} \mathrm{Mn}$ and ${ }^{64} \mathrm{Cu}$ against serum has been evaluated previously 
and found to be excellent [15,28]. For these reasons, high serum stability of both surface-labelled and remote-loaded liposomes was expected.

The impact of the ionophore concentration on the loading rate was investigated using radio-TLC (Fig. 2C). The loading rate was shown to increase with increasing ionophore concentration. The metal ion content of the loading rate assay was estimated to be about $4.3 \mu \mathrm{M}$ metal ions, including $0.27 \mu \mathrm{M} \mathrm{Mn}$. Thus, addition of $2 \mu \mathrm{M}$ ionophore represents a small excess compared to $\mathrm{Mn}$ but is insufficient to chelate the total number of cations present. Hence, by adding 10-25-fold higher ionophore concentrations, all cations are likely to be chelated by the ionophore and the loading completes within 5-30 min (Fig. 2C). The loading rate and optimal amount of ionophore thus depends on the metal ion content of the sample and therefore the radionuclide purity. Remote loading of ${ }^{64} \mathrm{Cu}$ is described in-depth in previous publications and not discussed here [7].

Based on these findings, a conserved ionophore/lipid ratio of $20 \mu \mathrm{M} / 10 \mathrm{mM}$ was used for remote loading ${ }^{52} \mathrm{Mn}$ into the liposomes used for in vivo studies.

Surface labeling of ${ }^{64} \mathrm{Cu}$ and ${ }^{52} \mathrm{Mn}$ : In this method, radiolabeling was facilitated by a high affinity chelator (DOTA) which had been covalently bound to a lipid that was incorporated into the liposome surface (Figure 1). This method has been described by Seo et al. [18]. For this purpose, the lipid conjugate DOTA-DSPE was synthesized, as the DSPE anchor had been previously shown to be stably embedded in liposome membranes composed of HSPC, Cholesterol and DSPE-PEG2k [18]. Initially, radiolabeling was conducted at $13 \mathrm{MBq}{ }^{52} \mathrm{Mn} / \mathrm{mL}$ using $10 \mathrm{mM}$ liposomes, which resulted in partial labeling (Fig. 2D). By doubling the lipid concentration, and hence the amount of DOTA-DSPE, quantitative radiolabeling (>95\%) was obtained within the 3 hour incubation period. For ${ }^{64} \mathrm{Cu}$, complete loading (>94\% on SEC and $>99.5 \%$ on TLC) was obtained for both 10 and 20 $\mathrm{mM}$ liposomes after 1 hour, and the loading efficiency remained high after 2 and 3 hours of incubation (data not shown). For both ${ }^{52} \mathrm{Mn}$ and ${ }^{64} \mathrm{Cu}$, a 24 hour EDTA challenge of the surface labeled liposomes resulted in less than $4 \%$ decrease in the loading efficiency. The observed loading efficiency and stability of the DOTA-DSPE functionalized liposomes were fully comparable with remote loaded liposomes for both ${ }^{52} \mathrm{Mn}$ and ${ }^{64} \mathrm{Cu}$.

\subsection{In vivo evaluation}


All four liposome types were intravenously injected into CT26-tumor bearing mice. In all cases, $200 \mu \mathrm{L}$ liposome dispersion (20 mM lipid) was administered, corresponding to $160 \mu \mathrm{mol} \mathrm{lipid} / \mathrm{kg}$. This is a 5-fold higher lipid dose than normally used for imaging in our group [7,25,29]. Doses within this range may suffer less first pass clearance [30]. Representative PET/CT images of the ${ }^{52} \mathrm{Mn}$ - and ${ }^{64} \mathrm{Cu}$-liposome scans at the different time-points are illustrated in Figure 3. Regions-ofinterest were marked and quantified (Figure 4A-E) and compared to post-mortem gamma-counted activity levels (Figure 4F). All accumulation values are reported as percent injected dose per gram tissue $(\% \mathrm{ID} / \mathrm{g})$. The comparison of the four liposome types was used to assess the stability of the ${ }^{64} \mathrm{Cu}$-DOTA and ${ }^{52} \mathrm{Mn}$-DOTA chelates. Liposomes represent a unique platform for such in vivo analyses as they allow the sequestration of a given radiometal-chelate into two isolated compartments, encapsulated or surface-conjugated. The encapsulated remote-loaded chelate is completely shielded from interactions with bloodstream components, preventing transchelation of free radiometal and enabling immediate reuptake by resident free DOTA in case of release from the chelate. On the other hand, the surface-conjugated chelate, DOTA-DSPE, is situated at the lipid bilayer interface and is in contact with the bloodstream, making it vulnerable to the conditions that might cause instabilities of the chelate during in vivo imaging. Further, since both types are longcirculating, this setup allows their comparison and analysis of stability differences over hours to days, providing a scenario that mirrors a realistic preclinical/clinical setting.

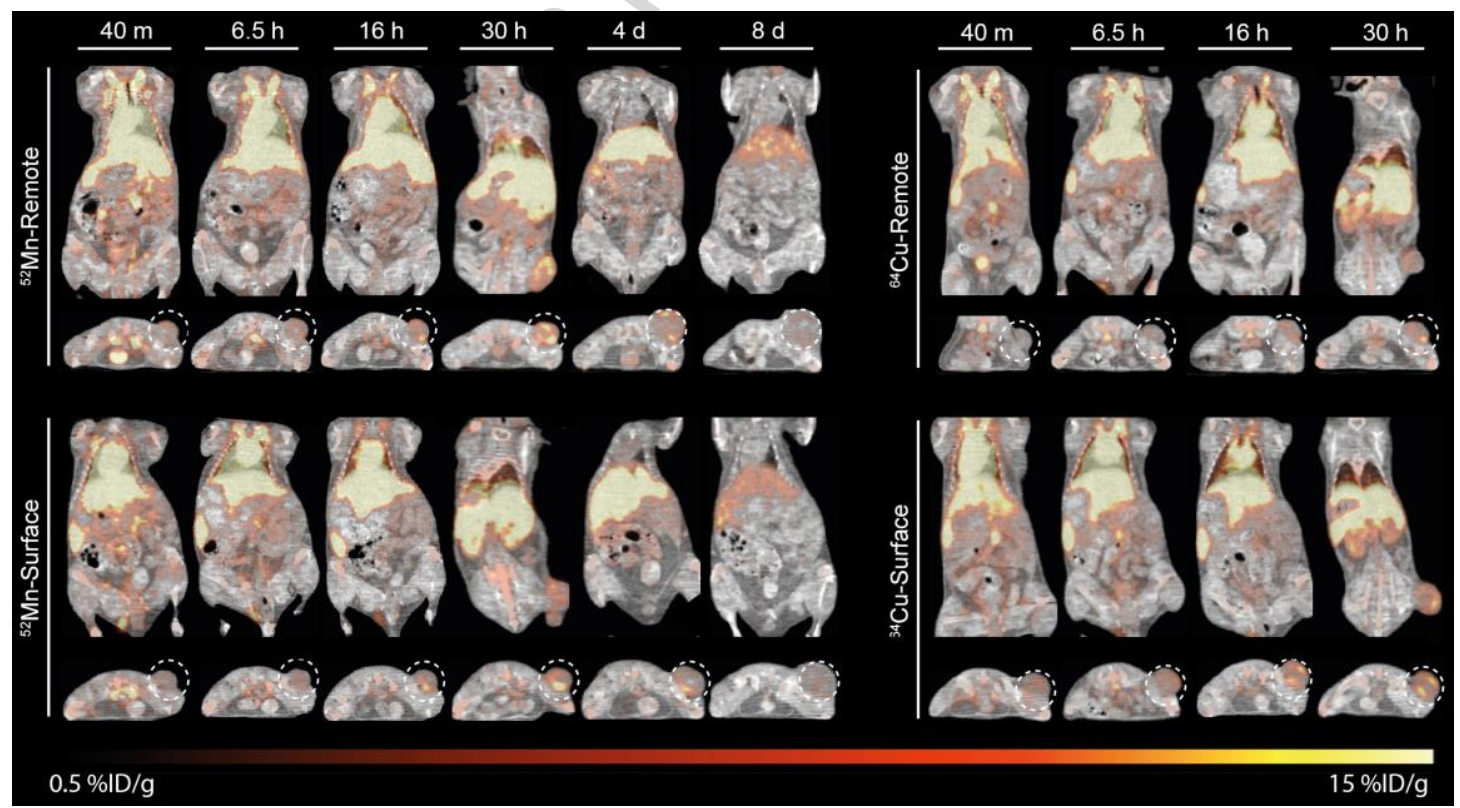


Figure 3: Coronal and transverse PET/CT images Balb/C mice carrying CT26 tumors injected with surface or remote loaded liposomes. Images recorded after $40 \mathrm{~min}, 6.5$ hours, 16 hours, 30 hours, 4 days and 8 days are shown for ${ }^{52} \mathrm{Mn}$-labelled liposomes and after $40 \mathrm{~min}, 6.5$ hours, 16 hours and 30 hours for ${ }^{64} \mathrm{Cu}$-labelled liposomes. Tumors are highlighted in the transverse images by a dashed circle.
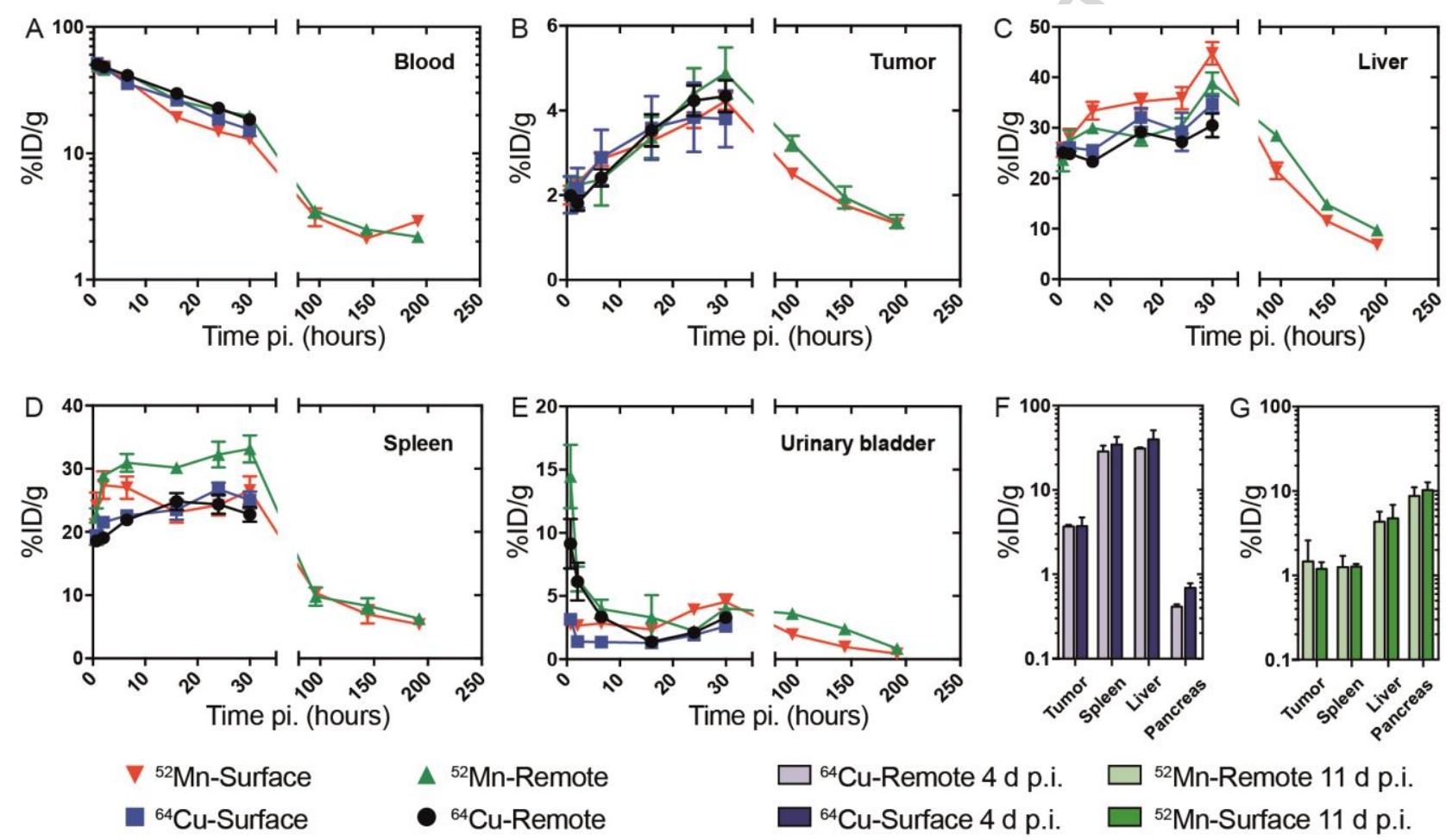

- ${ }^{52} \mathrm{Mn}$-Remote

$\square{ }^{64} \mathrm{Cu}$-Remote 4 d p.i.

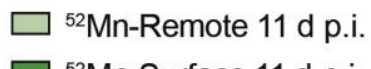

$\square{ }^{64} \mathrm{Cu}$-Surface 4 d p.i.

${ }^{52} \mathrm{Mn}-$ Surface $11 \mathrm{~d}$ p.i.

Figure 4: Biodistribution of remote and surface labeled liposomes based on PET imaging (A-E) or organ well counting (F-G). The accumulation (\% ID/g) in blood (A), tumor (B), liver (C), spleen (D) and urinary bladder (E) is shown as a function of time for surface or remote labeled liposomes for both ${ }^{64} \mathrm{Cu}$ and ${ }^{52} \mathrm{Mn}$. (F-G) Biodistribution of remote and surface labeled liposomes based on organ well counting. The animals were sacrificed 4 days and 11 days post injection for the ${ }^{64} \mathrm{Cu}$ and ${ }^{52} \mathrm{Mn}$ liposome groups respectively. The results are reported as mean and SEM $(A-E n=5, F-G n=3)$.

Analysis of chelate stabilities: Radioactivity levels by PET and ex vivo well-counting for all analyzed organs are seen in figure 4. Overall, the four liposome types were observed to follow similar clearance from the blood pool, with little difference between them (figure 4A, for all $p$ - 
values, see Supplementary Materials S3). The most consistent difference was between ${ }^{52} \mathrm{Mn}$ surface and the two remote-loaded formulations, where ${ }^{52} \mathrm{Mn}$-surface showed significantly lower blood values $(\mathrm{p}<0.01)$ at $6.5,16,24$ and $30 \mathrm{~h}$ compared with ${ }^{52} \mathrm{Mn}$-remote. A similar pattern of reduced blood levels was observed for ${ }^{64} \mathrm{Cu}$-surface compared to ${ }^{64} \mathrm{Cu}$-remote $(6.5$ hours: $p<$ 0.0001, 16 hours: $p=0.03$ and 24 hours: $p=0.004$ ). The two remote-loaded formulations, which were expected to have the most stable radiolabels due to their shielding from the surroundings, exhibited largely identical blood values, demonstrating the stability of these radiolabels. No clear biphasic elimination pattern could be determined for the liposomes. With a monophasic exponential fit from $0-30 \mathrm{~h}$, plasma half-lives were determined to be $20.3 \pm 1.2 \mathrm{~h}\left({ }^{64} \mathrm{Cu}\right.$-remote, $\mathrm{r}^{2}=0.99 \pm$ $0.00), 17.2 \pm 2.9 \mathrm{~h}\left({ }^{64} \mathrm{Cu}\right.$-surface, $\left.\mathrm{r}^{2}=0.99 \pm 0.01\right), 21.3 \pm 2.4 \mathrm{~h}\left({ }^{52} \mathrm{Mn}\right.$-remote, $\left.\mathrm{r}^{2}=0.96 \pm 0.03\right)$ and $14.4 \pm 1.2 \mathrm{~h}\left({ }^{52} \mathrm{Mn}\right.$-surface, $\left.\mathrm{r}^{2}=0.96 \pm 0.01\right)$. These half-lives are similar or slightly longer than what is typically observed for stealth liposomes in murine models by our group [7,8,25,29]. ${ }^{52} \mathrm{Mn}$ surface was found to have a sigifically shorter bloodstream half-life $(14.4 \mathrm{~h})$ than the other three liposome types, differing significantly from ${ }^{64} \mathrm{Cu}$-remote $(p=0.0019)$ and ${ }^{52} \mathrm{Mn}$-remote $(p=$ 0.0004), but not from ${ }^{64} \mathrm{Cu}$-surface $(p=0.19)$. In summary, the in vivo PET blood data showed generally faster elimination of the radiolabel for the two surface-labeled types, with resulting lower blood values and half-lives. This was more pronounced for ${ }^{52} \mathrm{Mn}$-surface than for ${ }^{64} \mathrm{Cu}$-surface. Accordingly, the blood data suggest that the ${ }^{52} \mathrm{Mn}$-DOTA chelate may be unstable when exposed to plasma components. The possible mechanisms of this indicated instability are currently unknown and will require further studies. From the obtained data, it is inconclusive whether this also applies to ${ }^{64} \mathrm{Cu}$-DOTA.

For the remaining organs, no clearly interpretable patterns were found, except for the urinary bladder. The radioactivity in the urine was observed to be markedly higher for ${ }^{64} \mathrm{Cu}$-remote and ${ }^{52} \mathrm{Mn}$-remote in the first 5 hours of imaging. Since chelates of radionuclides are known to undergo renal excretion [25], this could stem from limited liposomal rupture and release of cargo as a result of opsonization in the first hours after injection [31]. With chelates bound to lipid molecules, as is the case for the two surface-labeled types, such renal excretion would be unlikely. High initial urinary excretion of free radionuclide chelates inside liposomes has been previously observed [32]. In addition, significant difference was found between ${ }^{64} \mathrm{Cu}$-surface and ${ }^{52} \mathrm{Mn}$-surface at all time points beyond $40 \mathrm{~min}$, with ${ }^{52} \mathrm{Mn}$-surface showing higher urinary excretion. This may also hint at limited in vivo stability of the ${ }^{52} \mathrm{Mn}$-DOTA. One should note that quantitative evaluation 
of renal excretion by PET imaging has limited validity without correction in regards to urinary output etc. but this was not feasible in our current setup.

The ex vivo data for ${ }^{64} \mathrm{Cu}$-remote and ${ }^{64} \mathrm{Cu}$-surface (figure $4 \mathrm{~F}$ ) were tested against each other with no significant differences found, except for pancreas $(p=0.03)$. Specific pancreatic uptake of free ${ }^{64} \mathrm{Cu}$ has to our knowledge not been previously reported. For the ${ }^{52} \mathrm{Mn}$-liposomes, no significant differences were found. Accordingly, the well-counting data show similar biodistribution of surface versus remote loading for both radionuclides. This supports that the surface DOTA chelates are sufficiently stable for quantitative imaging with ${ }^{64} \mathrm{Cu}$. The high pancreatic uptake of ${ }^{52} \mathrm{Mn}$ at $11 \mathrm{~d}$ (Figure $4 \mathrm{~F}$ ) indicates that ${ }^{52} \mathrm{Mn}$ may be extracted from DOTA after metabolism of the liposomes, and end up in the pancreas, a known sink organ for free ${ }^{52} \mathrm{Mn}$ [14]. This also hints at a somewhat compromised in vivo stability of ${ }^{52} \mathrm{Mn}$-DOTA.

In both cases of surface-labeling, there is the theoretical possibility of migration of the radiolabeled lipids to other endogenous sites. This however, is not expected to occur for chelatorfunctionalized lipids with double C18 anchors [18]. In addition, the slightly faster clearance of the surface-labeled liposomes could be caused by increased uptake by immune cells due to the presence of charged DOTA on the surface. For this reason we measured complement activation of the DOTA1\% liposomes (DOTA on surface) and compared with LIP780 (DOTA in aqueous compartment). For full results, see Supplementary Materials S4. Overall, a 2.1 and 1.6-fold increase in SC5b-9 compared to background was observed for the DOTA1\% and LIP780 formulation respectively. This is a less pronounced activation profile compared to results published by Wibroe et al. that reported a 2-40 fold increase in SC5b-9 levels for a range of liposomal doxorubicin formulations [33]. Accordingly, surface-functionalized DOTA causes slightly higher complement activation, but whether this limited effect could be a factor in the enhanced clearance is currently unknown.

In consequence, our results indicate that ${ }^{52} \mathrm{Mn}$-DOTA may not be a suitable chelate for preclinical in vivo imaging. In opposition to this, Graves et al. reported limited uptake in the pancreas $(2.5 \% \mathrm{ID} / \mathrm{g})$ during long-term imaging (5 days) with exposed ${ }^{52} \mathrm{Mn}-\mathrm{DOTA}$ [14], and our own group previously found excellent serum stability in vitro [15]. The observed high serum stability of the chelate indicates that competition from endogenous metals in the blood does not displace ${ }^{52} \mathrm{Mn}$ from DOTA to a significant degree. Acordingly, fFurther studies should fully clarify the status of ${ }^{52} \mathrm{Mn}$-DOTA. 
Whether or not DOTA should continue to be the chelator of choice for ${ }^{64} \mathrm{Cu}$ in preclinical and clinical nuclear imaging is a source of much debate. DOTA is commercially available in multiple bifunctional forms, and chelates ${ }^{64} \mathrm{Cu}$ at room temperature and significant levels of knowledge on it use exist. However, several studies have reported transchelation of ${ }^{64} \mathrm{Cu}$ in vivo as well as reduced PET signal contrast between target and non-target organs when compared to other chelators $[34,35]$. This is in contrast to a generally reported high serum stability of the ${ }^{64} \mathrm{Cu}$ DOTA chelate [36,37]. It has been suggested that the facile reduction of $\mathrm{Cu}(\mathrm{II})$ to $\mathrm{Cu}(\mathrm{I})$, with consequent dechelation, may be implicated in the in vivo instability [38]. Since $\mathrm{Mn}$ (II) is fairly easily converted to $\mathrm{Mn}(\mathrm{IV})$, it may be speculated that redox processes also play a role in the observed instability of ${ }^{52} \mathrm{Mn}$-DOTA. In spite of the apparent in vivo instability of ${ }^{64} \mathrm{Cu}$-DOTA, it is successfully employed in the clinic with good image quality [39,40]. In this study we found some evidence that a ${ }^{64} \mathrm{Cu}$-DOTA complex conjugated to the surface of liposomes fared differently than a ${ }^{64} \mathrm{Cu}$-DOTA complex shielded within such liposomes, which may indicate compromised stability of the complex. However, the effect was generally not significant. Although free ${ }^{64} \mathrm{Cu}$ is known to accumulate in liver and some tumors, it is rapidly removed from the bloodstream upon injection and does not accumulate significantly in spleen [15,41]. Our results showed no clear pattern of significant difference between the blood stream circulation and splenic uptake of ${ }^{64} \mathrm{Cu}$-surface and ${ }^{64} \mathrm{Cu}$-remote, indicating no or little release of free ${ }^{64} \mathrm{Cu}$. Overall, our results do not clearly show whether ${ }^{64} \mathrm{Cu}$-DOTA is stable in vivo or not, but no clear evidence of in vivo instability was observed. Although this chelate may be demonstrated to be less stable than with other chelators, such as CB-TETA, NOTA, DIAMSAR and NODAGA, our results support that this is unlikely to have any substantial effect in a practical in vivo setting.

Post-distribution trafficking of ${ }^{52} \mathrm{Mn}$-radiolabels: Due to the long physical half-life of ${ }^{52} \mathrm{Mn}$, ${ }^{52} \mathrm{Mn}$-remote and ${ }^{52} \mathrm{Mn}$-surface could be imaged beyond the usual 2-3 days of liposome PET imaging that we typically perform. At the 4, 6 and 8 day time points, the blood radioactivities were found to have stabilized around $2-4 \% \mathrm{ID} / \mathrm{g}$. This indicates that some transport of ${ }^{52} \mathrm{Mn}$ into the bloodstream may occur. This is supported by Graves et al. who found the blood concentration to be around 4\% ID/g at the 96 hour time-point after injection of free ${ }^{52} \mathrm{Mn}$ [14]. We observed an average of $3.3 \pm 1.0 \% \mathrm{ID} / \mathrm{g}$ at this time. We found no significant difference between the two types at these late time-points. 
The tumor accumulation of the two ${ }^{52} \mathrm{Mn}$-labeled types increased until 30 hours followed by a drop in values at later time-points. This demonstrated that radionuclides that are taken up in tumor tissue can undergo elimination from the tumor, and that this elimination occurs independently of whether the radionuclide-chelator complex is free or conjugated to a lipid. This was also recently observed by Seo et al. for liposomes surface-labeled with ${ }^{89} \mathrm{Zr}$ [11]. ${ }^{52} \mathrm{Mn}$-remote exhibited a tumor clearance half-life of $80 \pm 11 \mathrm{~h}\left(\mathrm{r}^{2}=0.98 \pm 0.03\right)$, and ${ }^{52} \mathrm{Mn}$-surface a half-life of $106 \pm 10 \mathrm{~h}\left(\mathrm{r}^{2}=1.00 \pm 0.00\right)$. These were calculated by exponential regression on the 4,6 and 8 day time-points. The clearance half-lives were significantly different $(p=0.027)$, indicating that the position and chemical form of the radiolabel influences clearance from tumor tissue. This supports the findings of Seo et al. where the length of the linker (buried versus exposed chelate) significantly affected the excretion from the tumor [11]. The faster clearance of ${ }^{52} \mathrm{Mn}$-remote may be caused by destruction of the liposomes after cellular uptake, followed by easier washout of the highly hydrophilic ${ }^{52} \mathrm{Mn}$-DOTA chelate. Long-term imaging of the two ${ }^{52} \mathrm{Mn}$ liposome types showed elimination from the liver and spleen after 30 hours at similar rates for the two.

With the current interest in using radiolabeled liposomes as theranostic PET radiotracers for predicting the presence of the EPR effect in a clinical setting in human subjects, the choice of radionuclide becomes relevant. Due to the longer time-span of biodistribution in humans, longer-lived radionuclides may be preferable. In this case, a reduced patient dose is received if the accumulated radioactivity is subsequently eliminated, especially from highly accumulating organs as liver and spleen. These results show that this may be the case. In order to showcase the dosimetric significance of elimination from organs and the general use of long-lived PET radionuclides dosimetry calculations were made. These are presented in supplementary materials S5, and showed that the received dose from using ${ }^{52} \mathrm{Mn}$ or ${ }^{64} \mathrm{Cu}$ depends heavily on the time of image recording. With imaging times after around 69 hours post-injection, ${ }^{52} \mathrm{Mn}$ was found to have favorable dosimetry.

General biodistribution: The highest observed tumor accumulation values for all four liposome types were around $4 \% \mathrm{ID} / \mathrm{g}$, with limited significant difference at all time-points between the groups. For ${ }^{52}$ Mn remote was observed a mor acemmation value of arome $6.4 \pm 1.0 \% \mathrm{FD} / \mathrm{g}$ at 30 $\mathrm{h}$, and a significantly higher level than the other three groups from 6.5 to $30 \mathrm{~h}$. The reasen for this was that two temors in the ${ }^{52}$ Mn-remote group exhibited higher uptake of the radiolabeled liposomes. We speculate that this may have been due to their larger size which corresponded with 
higher accumulation per mass (\%/D/g) (see Supplementary Materials S6 for discussion). Previous studies have reported higher liposome $\% \mathrm{ID} / \mathrm{g}$ in smaller tumors as compared to larger tumors, which is in disagreement with our data $[8,32]$. Where we used the tumor cell-line CT26 (colon earcinøma), other studies have used NCI H727 (neuroendocrine tumor, [8]) or KB (squamous cell eancer, [32]), so tumor type may have some influence. Syngenic cancer models tend to have much less intratmoral necrosis compared to xenografts, especially for larger tmmors [42], which may explain the higher mean uptake per mass in smaller tmmors reported in some studies. Accordingly, we do not consider the higher observed tmmor uptake of ${ }^{52} \mathrm{Mn}$-remote to be a reflection of liposomat properties. The peak tumor accumulations reached by all four groups are similar to previously reported values for liposomes in murine tumor xenograft models [11,25,29]. A discussion of tumor accumulation data can be found in Supplementary Materials S6.

Liver accumulation was similar for all four liposomes types, with high initial values around $25 \% \mathrm{ID} / \mathrm{g}$, increasing until 30 hours, reaching values around 30-45\% were higher than typically reported data for liposomes in murine models, potentially due to the mice strain used in the study at hand. Further studies are needed to decipher the mechanisms underlying this observation, which is beyond the scope of this paper. Few clear patterns of significant difference between the four liposome types were identified, but ${ }^{52} \mathrm{Mn}$-surface exhibited higher liver accumulation than the other types and was different from ${ }^{64} \mathrm{Cu}$-remote (lowest liver accumulation) at 6.5, 24 and 30 hours ( $\mathrm{p}<0.01$ in all cases). This may be a result of both release of ${ }^{52} \mathrm{Mn}$ from the DOTA-DSPE chelate with subsequent liver accumulation, or because of immune cell interactions with the chemically distinct surface DOTA moieties. However, no such pattern was observed for ${ }^{64} \mathrm{Cu}$-surface. Free ${ }^{52} \mathrm{Mn}$ has been reported to accumulate in liver [14]. Spleen accumulation was characterized by high initial accumulation of the two ${ }^{52} \mathrm{Mn}$ liposomes with higher activity of ${ }^{52} \mathrm{Mn}$ remote compared to the other liposome types at almost all time-points. A clear pattern of significantly higher splenic accumulation was found for ${ }^{52} \mathrm{Mn}$-remote compared to ${ }^{64} \mathrm{Cu}$-remote at all time-points $(p<0.05)$. However, there is no clear reason for this, as these two liposome types should have identical surface characteristics.

In addition to the \% ID/g values reported here, absolute accumulation data (\%ID) can be found in Supplementary materials S7. In this section the total body radioactivity as a function of time is also provided (Fig. S3E+F). The total radioactivity accounted for was around $100 \%$ at the start of scans and was eliminated with a half-life of about 50 hours, largely independent of liposome type. 
The ex vivo accumulation data for tumor, spleen and liver (Figure 4F) mirrored the values obtained by PET imaging, with somewhat lower values for well-counting of ${ }^{52} \mathrm{Mn}$ liposomes, due to the passing of an additional three days after the last PET time-point ( 8 days). Pancreas was included since free ${ }^{52} \mathrm{Mn}$ has been reported to accumulate strongly in this organ [14], while free ${ }^{64} \mathrm{Cu}$ is known to accumulate in liver [20,41].

\section{Conclusion}

We have successfully developed an ionophore assisted method for remote loading of stealth liposomes with the long-lived PET isotope ${ }^{52} \mathrm{Mn}$. Optimal loading conditions (>95\% loading efficiency) were achieved either by reduction of intra-lumen $\mathrm{pH}$ of the liposomes or by use of chloro- or iodo-substituted analogues of the ionophore, 8-hydroxyquinoline. In addition, protocols for surface labelling of liposomes with ${ }^{64} \mathrm{Cu}$ or ${ }^{52} \mathrm{Mn}$ were developed.

Liposomes remote-loaded or surface-labeled with ${ }^{64} \mathrm{Cu}$ or ${ }^{52} \mathrm{Mn}$ were compared headto-head in an in vivo biodistribution study in Balb/C mice, in order to investigate the in vivo stability of the ${ }^{64} \mathrm{Cu}$-DOTA and ${ }^{52} \mathrm{Mn}$-DOTA chelates. The biodistribution of all four liposome types was similar overall, but with remote loaded liposomes circulating with longer plasma halflives than their surface labeled counterparts. ${ }^{52} \mathrm{Mn}$-surface exhibited a significantly shorter plasma half-life than ${ }^{52} \mathrm{Mn}$-remote $(14.4 \pm 1.2 \mathrm{~h}$ versus $21.3 \pm 2.4 \mathrm{~h})$, showing that ${ }^{52} \mathrm{Mn}$-DOTA may be unstable when exposed to the bloodstream and potentially unsuitable for use in quantitative studies. The cause of this in vivo instability is currently unknown. ${ }^{64} \mathrm{Cu}$-surface also showed faster clearance from the bloodstream than ${ }^{64} \mathrm{Cu}$-remote, but the difference was not significant $(17.2 \pm 2.9 \mathrm{~h}$ versus $20.3 \pm 1.2 \mathrm{~h}$ ). Accordingly, our results support that ${ }^{64} \mathrm{Cu}$-DOTA is suitable for both qualitative and quantitative imaging.

\section{Acknowlegement}

The Danish Strategic Research Council, the Technical University of Denmark (DTU), the Danish National Advanced Technology Foundation, European Research Council (ERC), and the Lundbeck Foundation kindly provided financial support for this project. 


\section{References}

1. Sun T, Zhang YS, Pang B, Hyun DC, Yang M, Xia Y. Engineered nanoparticles for drug delivery in cancer therapy. Angew Chemie - Int Ed. 2014; 53(46):12320-64.

2. Fang J, Nakamura H, Maeda H. The EPR effect: Unique features of tumor blood vessels for drug delivery, factors involved, and limitations and augmentation of the effect. Adv Drug Deliv Rev. 2011; 63(3):136-51.

3. Hansen AE, Petersen AL, Henriksen JR, et al. Positron emission tomography based elucidation of the enhanced permeability and retention effect in dogs with cancer using copper-64 liposomes. ACS Nano. 2015; 9(7):6985-95.

4. Ehlerding EB, Goel S, Cai W. Cancer theranostics with $64 \mathrm{Cu} / 177 \mathrm{Lu}$-loaded liposomes. Eur J Nucl Med Mol Imaging. 2016; 43(5):938-40.

5. Van der Geest T, Laverman P, Metselaar JM, Storm G, Boerman OC. Radionuclide imaging of liposomal drug delivery. Expert Opin Drug Deliv. 2016; 13(9):1231-42.

6. Petersen AL, Hansen AE, Gabizon A, Andresen TL. Liposome imaging agents in personalized medicine. Adv Drug Deliv Rev. 2012; 64(13):1417-35.

7. Henriksen JR, Petersen AL, Hansen AE, et al. Remote loading of $64 \mathrm{Cu} 2+$ into liposomes without the use of ion transport enhancers. ACS Appl Mater Interfaces. 2015; 7(41):22796806.

8. Petersen AL, Henriksen JR, Binderup T, et al. In vivo evaluation of PEGylated $64 \mathrm{Cu}-$ liposomes with theranostic and radiotherapeutic potential using micro PET/CT. Eur J Nucl Med Mol Imaging. 2016; 43(5):941-52.

9. Barenholz Y. Doxil - The first FDA-approved nano-drug: Lessons learned. J Control Release. 2012; 160(2):117-34.

10. Van De Watering FCJ, Rijpkema M, Perk L, Brinkmann U, Oyen WJG, Boerman OC. Zirconium-89 labeled antibodies: A new tool for molecular imaging in cancer patients. Biomed Res Int. 2014; 2014:1-13.

11. Seo JW, Mahakian LM, Tam S, et al. The pharmacokinetics of Zr-89 labeled liposomes over extended periods in a murine tumor model. Nucl Med Biol. 2015; 42(2):155-63.

12. Braghirolli AMS, Waissmann W, Da Silva JB, Dos Santos GR. Production of iodine-124 and its applications in nuclear medicine. Appl Radiat Isot. 2014; 90:138-48.

13. Cal-González J, Herraiz JL, España S, Desco M, Vaquero JJ, Udías JM. Positron range 
effects in high resolution 3D PET imaging. 2009 IEEE Nucl Sci Symp Conf Rec. 2009; :2788-91.

14. Graves SA, Hernandez R, Fonslet J, et al. Novel preparation methods of 52Mn for immunoPET imaging. Bioconjug Chem. 2015; 26(10):2118-24.

15. Fonslet J, Tietze S, Jensen AI, Graves SA, Severin GW. Optimized procedures for manganese-52: Production, separation and radiolabeling. Appl Radiat Isot. 2017; 121:38-43.

16. Edmonds S, Volpe A, Shmeeda H, et al. Exploiting the metal-chelating properties of the drug cargo for in vivo positron emission tomography imaging of liposomal nanomedicines. ACS Nano. 2016; 10:10294-307.

17. Jai WS, Zhang H, Kukis DL, Meares CF, Ferrara KW. A novel method to label preformed liposomes with $64 \mathrm{Cu}$ for positron emission tomography (PET) imaging. Bioconjug Chem. 2008; 19(12):2577-84.

18. Seo JW, Mahakian LM, Kheirolomoom A, et al. Liposomal Cu-64 labeling method using bifunctional chelators: Poly(ethylene glycol) spacer and chelator effects. Bioconjug Chem. 2010; 21(7):1206-15.

19. Severin GW, Jørgensen JT, Wiehr S, et al. The impact of weakly bound ${ }^{89} \mathrm{Zr}$ on preclinical studies: non-specific accumulation in solid tumors and aspergillus infection. Nucl Med Biol. 2015; 42(4):360-8.

20. Jensen AI, Binderup T, Ek PK, et al. PET imaging with copper-64 as a tool for real-time in vivo investigations of the necessity for cross-linking of polymeric micelles in nanomedicine. J Label Compd Radiopharm. 2017; 60(8):366-74.

21. Jensen AI, Binderup T, Kumar EK P, Kjær A, Rasmussen PH, Andresen TL. Positron emission tomography based analysis of long-circulating cross-linked triblock polymeric micelles in a U87MG mouse xenograft model and comparison of DOTA and CB-TE2A as chelators of copper-64. Biomacromolecules. 2014; 15(5):1625-33.

22. Bartholomä MD. Recent developments in the design of bifunctional chelators for metalbased radiopharmaceuticals used in Positron Emission Tomography. Inorganica Chim Acta. 2012; 389:36-51.

23. Cai Z, Anderson CJ. Chelators for copper radionuclides in positron emission tomography radiopharmaceuticals. J Label Compd Radiopharm. 2014; 57(4):224-30.

24. Shokeen M, Anderson CJ. Molecular imaging of cancer with copper-64 radiopharmaceuticals and positron emission tomography (PET). Acc Chem Res. 2009; 42(7):832-41. 
25. Petersen AL, Binderup T, Rasmussen P, et al. 64Cu loaded liposomes as positron emission tomography imaging agents. Biomaterials. 2011; 32(9):2334-41.

26. Kaiser SM, Escher BI. The evaluation of liposome-water partitioning of 8-hydroxyquinolines and their copper complexes. Environ Sci Technol. 2006; 40(6):1784-91.

27. Gaddy DF, Lee H, Zheng J, Jaffray DA, Wickham TJ, Hendriks BS. Whole-body organ-level and kidney micro-dosimetric evaluations of (64)Cu-loaded HER2/ErbB2-targeted liposomal doxorubicin ((64)Cu-MM-302) in rodents and primates. EJNMMI Res. 2015; 5:24.

28. De Silva RA, Jain S, Lears KA, et al. Copper-64 radiolabeling and biological evaluation of bifunctional chelators for radiopharmaceutical development. Nucl Med Biol. 2012; 39(8):1099-104.

29. Petersen AL, Binderup T, Jolck RI, et al. Positron emission tomography evaluation of somatostatin receptor targeted $64 \mathrm{Cu}$-TATE-liposomes in a human neuroendocrine carcinoma mouse model. J Control Release. 2012; 160(2):254-63.

30. Laverman P, Brouwers AH, Dams ET, et al. Preclinical and clinical evidence for disappearance of long-circulating characteristics of polyethylene glycol liposomes at low lipid dose. J Pharmacol Exp Ther. 2000; 293(3):996-1001.

31. Serna M, Giles JL, Morgan BP, Bubeck D. Structural basis of complement membrane attack complex formation. Nat Commun. 2016; 7:10587.

32. Harrington KJ, Rowlinson-Busza G, Syrigos KN, et al. Influence of tumour size on uptake of (111)ln-DTPA-labelled pegylated liposomes in a human tumour xenograft model. $\mathrm{Br} \mathbf{J}$ Cancer. 2000; 83(5):684-8.

33. Wibroe PP, Ahmadvand D, Oghabian MA, Yaghmur A, Moghimi SM. An integrated assessment of morphology, size, and complement activation of the PEGylated liposomal doxorubicin products Doxil®, Caelyx®, DOXOrubicin, and SinaDoxosome. J Control Release. 2016; 221:1-8.

34. Boswell CA, Sun X, Niu W, et al. Comparative in vivo stability of copper-64-labeled crossbridged and conventional tetraazamacrocyclic complexes. J Med Chem. 2004; 47(6):146574.

35. Ghosh SC, Pinkston KL, Robinson H, et al. Comparison of DOTA and NODAGA as chelators for 64Cu-labeled immunoconjugates. Nucl Med Biol. 2015; 42(2):177-83.

36. Kang CM, Koo HJ, Lee KC, et al. A vascular endothelial growth factor 121 (VEGF121)based dual PET/optical probe for invivo imaging of VEGF receptor expression. Biomaterials. 
2013; 34(28):6839-45.

37. Hanaoka H, Tominaga $\mathrm{H}$, Yamada K, et al. Evaluation of 64Cu-labeled DOTA-d-Phe1-Tyr 3 -octreotide (64Cu-DOTA-TOC) for imaging somatostatin receptor-expressing tumors. Ann Nucl Med. 2009; 23(6):559-67.

38. Woodin KS, Heroux KJ, Boswell CA, et al. Kinetic inertness and electrochemical behavior of copper(II) tetraazamacrocyclic complexes: Possible implications for in vivo stability. Eur $\mathbf{J}$ Inorg Chem. 2005; (23):4829-33.

39. Johnbeck CB, Knigge U, Loft A, et al. Head-to-head comparison of 64Cu-DOTATATE and 68Ga-DOTATOC PET/CT: a prospective study of 59 patients with neuroendocrine tumors. J Nucl Med. 2016; :1-31.

40. Pfeifer A, Knigge U, Mortensen J, et al. Clinical PET of neuroendocrine tumors using $64 \mathrm{Cu}-$ DOTATATE: first-in-humans study. J Nucl Med. 2012; 53(8):1207-15.

41. Jørgensen JT, Persson M, Madsen J, Kjær A. High tumor uptake of 64Cu: Implications for molecular imaging of tumor characteristics with copper-based PET tracers. Nucl Med Biol. 2013; 40(3):345-50.

42. Beverly A. Teicher. Tumor models in cancer research, 2nd ed. New York: Springer; 2011. 
Graphical abstract

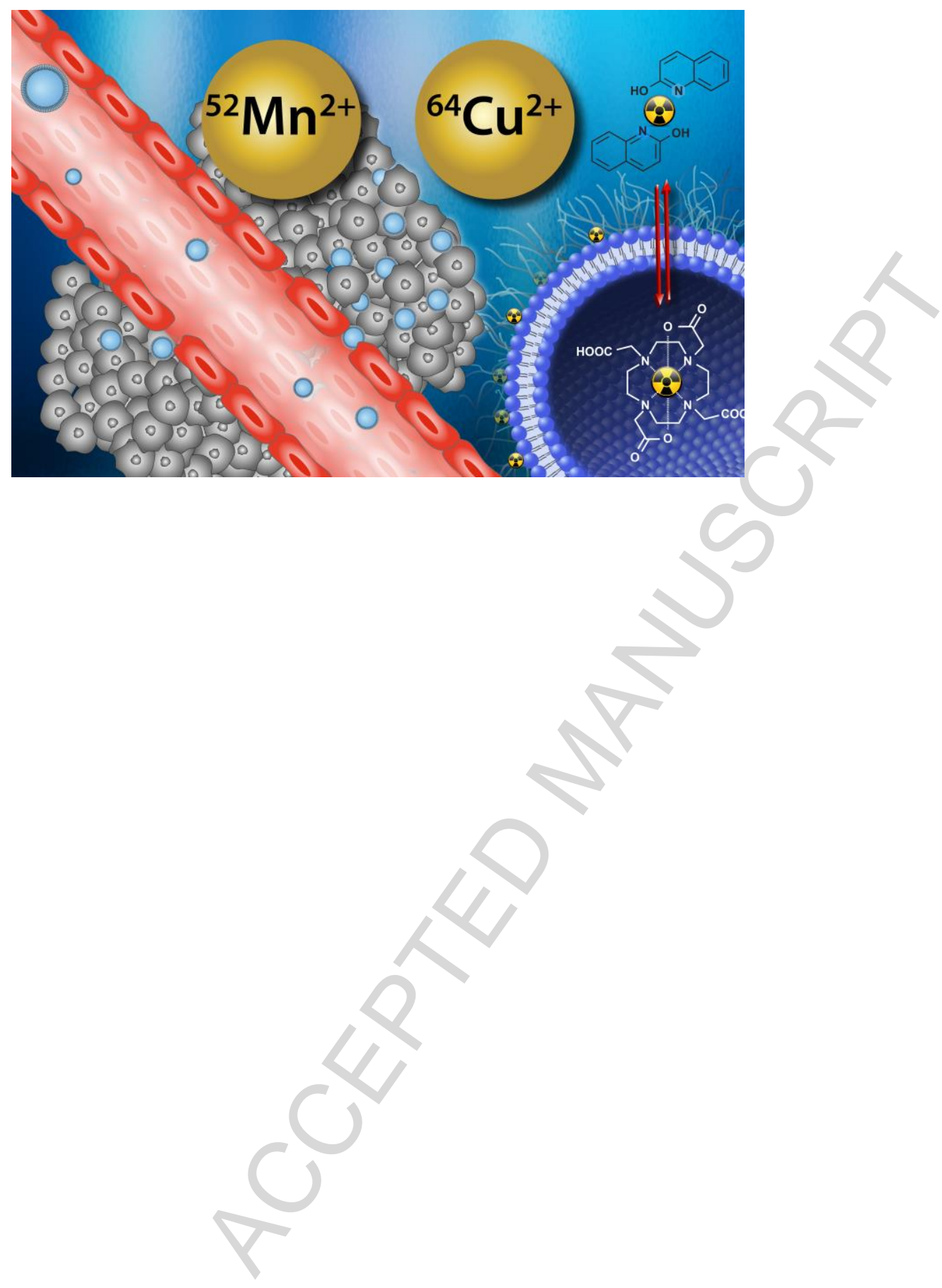

